\title{
The Current and Future Role of Drugs and Probiotics in the Management of Inflammatory Bowel Disease
}

\author{
Maricelma da Silva Soares de Souza ${ }^{*}$, Sandra Maria Barbalho ${ }^{1,2}$, \\ Ricardo de Alvares Goulart ${ }^{3}$, Antonely de Cássio Alves de Carvalho ${ }^{4}$ \\ ${ }^{1}$ Department of Biochemistry and Pharmacology, School of Medicine, University of Marília, Marília, São Paulo, Brazil \\ ${ }^{2}$ Department of Biochemistry and Pharmacology, School of Medicine, University of Marilia and Food \\ Technology School (FATEC), Marília, São Paulo, Brazil \\ ${ }^{3}$ Department of Gastroenteology, University Hospital-UNIMAR, Marília, São Paulo, Brazil \\ ${ }^{4}$ Diagnostic Center in Gastroenterology, Ibaiti, Paraná, Brazil \\ Email: ${ }^{*}$ maricelma.soares.souza@gmail.com
}

Received 5 August 2015; accepted 23 August 2015; published 26 August 2015

Copyright (C) 2015 by authors and Scientific Research Publishing Inc.

This work is licensed under the Creative Commons Attribution International License (CC BY).

http://creativecommons.org/licenses/by/4.0/

(c) $\underset{\mathrm{EY}}{\mathbf{0}}$ Open Access

\section{Abstract}

Inflammatory Bowel Disease (IBD) and other auto-inflammatory disorders are conditions caused by chronic and persistent intestinal inflammation, which is mainly represented by Ulcerative Colitis (UC) or Crohn's Disease (CD), both of which typically arise as chronic inflammation of the gastrointestinal mucosa. Doctor's main focus for treating IBD is the decrease on inflammation processes when the disease is active and promotes the maintenance of inflammation at normal levels. However, to deal with these two parameters is not easy, because the drugs usually used are related to several side effects and they are not totally effective to reduce inflammation and to keep the remission. Authors agree that the therapy approach should include drugs, dietary intervention and use of alternative substances as probiotics. The standard treatment approach for patients with CD and UC is traditionally done with the use of anti-inflammatory agents, like corticosteroids, mesalamine, immunomodulators such as azathioprine and methotrexate, and biologic agents such as infliximab and others. Probiotics are known as viable micro-organisms (or live microorganisms or live microbial dietary supplements) that may promote beneficial physiologic or therapeutic properties when used correctly. The interest in the role of these substances in improving human health is the reason of several researches. They may be used to help the immune system, to control gastro-intestinal infections and to prevent several diseases. Prebiotics, symbiotics, and probiotics may be helpful as adjuvants in the treatment of IBD. Probiotics are normally well-tolerated and are associated with few side effects which are undoubtedly important in the treatment of any

${ }^{*}$ Corresponding author.

How to cite this paper: Souza, M.S.S., Barbalho, S.M., Goulart, R.A. and Carvalho, A.C.A. (2015) The Current and Future Role of Drugs and Probiotics in the Management of Inflammatory Bowel Disease. Journal of Biosciences and Medicines, 3, 76-85. http://dx.doi.org/10.4236/jbm.2015.38008 


\section{disease.}

\section{Keywords}

\section{Inflammatory Bowel Diseases, Immunomodulators, Biological Agents, Probiotics}

\section{Introduction}

The gastrointestinal system is the first safeguard against environmental agents, and is responsible for immune tolerance of microbiota that involves an ecosystem of microbes which co-exist in a symbiotic manner. Disruption among these microorganisms is related to Inflammatory Bowel Disease (IBD) and other auto-inflammatory disorders. IBD is a condition caused by chronic and persistent intestinal inflammation which is mainly represented by Ulcerative Colitis (UC) or Crohn's Disease CD), both of which typically arise as chronic inflammation of the gastrointestinal mucosa [1]-[3]. A chronic intermittent inflammatory process is typical in IBD patients and the flare periods alternate with periods of remission. UC and CD are clinically different in the bowel location, nature, and the histological patterns of the inflammatory lesions and occur normally in patients with genetic influence and its interaction with environmental stressors that may cause a deviant response by innate, adaptive, and tolerogenic immunity of the intestinal mucosa to dietary antigens or commensal microorganism. It is possible to find a condition of increased oxidative stress in both and in the inflammatory biomarkers leading to the colonic disarrangement. In CD the intestinal tissue is branded with a transmural inflammation from mouth to anus and the presence of lesions along the whole tract of the gut mucosa. It occurs as a skip pattern of the lesions where it is possible to find regular areas separated from inflammatory areas. Extra intestinal complications and the presence of granulomas, mainly in ileo-cecal or ileo-colic areas, are common. The other main form of IBD is represented by UC that manifests as a diffuse inflammation limited to the superficial layers of the colonic mucosa that extends from the rectum and rarely affects the colon and terminal ileum. Both conditions are inclined to the occurrence of pancolitis with megacolon and colon carcinoma. These conditions usually manifest in genetic susceptible people and involve an environmental trigger that unleashes an immune response in the gastrointestinal tract mucosa which is related to significant morbidity and mortality [4]-[13]. The IBD features include increased levels of intestinal pro-inflammatory cytokine, intestinal tissue disorders and severe clinical symptoms. The innate immune system capacity that responds appropriately to the pathogenic bacteria is associated with the activation of Pattern Recognition Receptors (PRRs). In healthy conditions the PRRs show a balance in the acute inflammatory response and may promote the bacteria elimination and resolution of the inflammation process. When the balance is lost, a chronic state that characterizes the IBD is installed and the chronic inflammation leads to tissue damage and epithelial cell necrosis. There is a subsequent activation of Toll-like receptors (TLRs) that are expressed by macrophages, dendritic cells and B cells and the different types have specific ligands. This activation is related to the impairment on the recognition of pathogenic and commensal bacteria and triggers overproduction of inflammatory cytokines in consequence of the activation of nuclear factor kappa beta $(\mathrm{NF} \kappa \mathrm{B})$ which is started by TLR4. Another Toll-like receptor is TLR9 that works as a sensor of bacteria and is important in many autoimmune disorders and in intestinal immune tolerance. Results from TLR9 activation are transcription of interferon regulatory factor 7 (IRF7) and expression of interferon- $\alpha$ (INF- $\alpha$ ) through I kappa B kinase $\alpha(\mathrm{IKK} \alpha)$. Subsequent to that, there is a phosphorylation of IKK $\beta$ that is related to the activation of protein $\mathrm{IkB}$, bound to the $\mathrm{p} 65 / \mathrm{p} 50$ dimer of the $\mathrm{NF} \kappa \mathrm{B}$ family transcription factors, and hampers their nuclear translocation. This cascade leads to the expression of the pro-inflammatory cytokines as interleukin (IL)-1 $\beta$, IL-6 and Tumor Necrosis Factor $\alpha$ (TNF- $\alpha$ ) and the production or nitric oxide [10] [14]-[20] [14]-[20]. Another possibility involves the phosphorylation of $\mathrm{NF} \kappa \mathrm{B}$-inducing kinase which phosphorylates IKK $\alpha$ alone. The consequence is the cleavage of another dimer of the $\mathrm{NF} \kappa \mathrm{B}$ family protein which induces the expression of other proteins, like the acetylcholine hydrolyzing enzyme acetylcholinesterase and the immune regulatory enzyme indoleamine 2, 3-dioxygenase. This other mechanism may be activated by innumerous known ligands. $\mathrm{NF} \kappa \mathrm{B}$ also works in additional receptors, as in the nicotinic acetylcholine receptor, suggesting relationship between the above mechanisms and anti-inflammatory TLR9 pathways [21]-[27]. Besides the pro-inflammatory condition that characterizes IBD, there is also a massive production of free radicals (oxidative 
stress), which leads to the progression of intestinal chronic inflammation. Low amounts of free radicals are important for the recognition of nutrients, commensal and pathogenic bacteria and for killing pathogens during immune response. The gastrointestinal tract must hold the redox balance in order to keep it in healthy conditions. Authors believe that the maintenance of an oxidative stress condition helps the expression and the progression of IBD, because it actives inflammation by inducing redox-sensitive signaling pathways and transcription factors. On the other hand, many inflammatory processes spring further amounts of free radical, leading to a "self-sustaining and auto-amplifying vicious circle" resulting in modifications of structural and functional gut barrier and change the response to commensal flora and pathogens [4]. The inflammatory process in IBD leads to an important impact on the patients, beyond intestinal symptoms. Consequences of this impact may be related to increased rates of depression, and reduced workforce participation in UC and CD patients. Another important point is the process of pain which is presented in the majority of IBD patients. This condition is a manifestation of the inflammatory conditions, once the cytokines and other mediators sensitize primary afferent neurons. However, the continuity of inflammation is not fully sufficient to explain the pain, because there are patients in remission that still carry on significant symptoms. It is believed that pain is an alarm related to the intensity and potency of noxious stimuli [28]-[32].

Doctor's main focus for treating IBD is the decreasing on inflammation processes, when the disease is active and promotes the maintenance of inflammation at normal levels. However, to deal with these two parameters is not easy because the drugs usually used are related to several side effects and they are not totally effective to reduce inflammation and to keep the remission. Authors agree that the therapy approach should include drugs, dietary intervention and use of alternative substances as probiotics.

\section{Methods}

This review intended to point the importance of probiotics as adjuvants to the treatment and maintenance of remission in IBD patients. This work was based on a survey of articles related to IBD and use of probiotics. We used the following databases: Pubmed, Medline, Scielo, Scopus and Lilacs. A retrospective search was carried out to identify relevant clinical trials or epidemiological studies and reviews limited to indexed scientific articles.

\section{Traditional Therapy for IBD}

IBD affects more than 1 million of people in the United States and an estimated 2.5 - 3 million people in Europe are affected, with a direct healthcare cost of 4.6 - 5.6 billions of Euros/year [33] [34]. New insights into the pathogenesis of IBD have been provided by three lines of research: 1) understanding the susceptibility of the genes related to the detection of bacterial components regulation of immune response, 2) understanding the break of tolerance by commensal microbiota, and 3) stringing the role of environmental factors as sanitation and hygiene. This current etiological hypothesis of IBD which argue that pathogenic intestinal bacteria and/or infectious agents initiate and perpetuate the inflammation of the gut in an individual with genetic vulnerability leading to impaired epithelial barrier function and abnormal mucosal immune responses [35]. The standard treatment approach for patients with CD and UC is traditionally done with the use of anti-inflammatory agents, like corticosteroids, mesalamine, immunomodulators such as azathioprine and methotrexate, and biologic agents such as infliximab and others. Glucocorticoids are potent anti-inflammatory with a central role in the treatment of diseases involving immune and inflammatory mechanisms like IBD. Current studies suggest that P38 mitogen-activated protein kinases (p38 MAPK) mediated synergism between Interleucin-10 (IL-10) and glucocorticoids improves desmosome straightness contributing to the recovery of intestinal epithelium and reducing luminal antigens contact with lamina propria in UC. This highlights the link between the intestinal epithelium in glucocorticoids-response in UC [36]. Therefore, the systemic effects of corticosteroids high doses or prolonged therapy include suppression of the hypothalamic-pituitary-adrenal, electrolyte abnormalities, hypertension, hyperglycemia, osteoporosis, myopathy, cataracts, stretch marks, ecchymoses and susceptibility to infections [37] [38]. Mesalazine, a 5-aminosalicylic acid (5-ASA) compound, is widely recognized as an important line of drugs for mildly to moderately active UC, because of its efficacy and safety [39]. Several formulations of oral mesalazine are available and primarily differentiated by the means of delivering active mesalazine to the colon. The timedependent release formulation of mesalazine (time-5-ASA) is coated with ethyl cellulose and begins to release 5-ASA in the duodenum; then the release is continued throughout the large intestine. On the other hand, the 
pH-dependent release formulation of mesalazine (pH-5-ASA) is coated with Eudragit-S and starts to release the drug in the terminal ileum or cecum, since the coating film breaks down at $\mathrm{pH} 7$ or higher [40]. High-dose treatments with these formulations are effective for induction of remission in patients with UC as compared to conventional dosages [41] [42]. A recent study revealed that the mucosal mesalazine concentration in the sigmoid colon in patients treated with $\mathrm{pH}-5$-ASA was higher than that in patients treated with time-5-ASA. These findings suggest that pH-5-ASA may be effective for active "UC in patients for whom time-5-ASA did not successfully induce or maintain remission" [43]. Currently, the exact molecular mechanism by which thiopurines may have immunosuppressive effects is not well-comprehended and it is possible to find several theories in the literature. One of them suggests that 6-thioguanine (6-TGN), a metabolite of azathioprine, accumulates in lymphocytes and interferes in the expression of inflammatory-related cytokines, including Tumor Necrosis Factor (TNF)-related apoptosis-inducing ligand, TNF receptor S7, and alpha-4-integrins, ultimately inhibiting the inflammatory response induced by T-cells in the intestinal lamina propria in patients with IBD [44] [45]. The use of methotrexate (MTX) is very common and most of them are: steroid dependant CD; maintenance of remission in steroid free $\mathrm{CD}$; azathioprine failures in $\mathrm{CD}$; in combination therapy with Anti-TNF agents in $\mathrm{CD}$; decreasing antibody formation to Anti-TNF therapy in $\mathrm{CD}$; management of fistulizing disease in $\mathrm{CD}$; and as well as induction and maintenance of remission in UC [46] [47]. MTX is largely used as a second line therapy after AZA failure. It may be useful in combination with Anti-TNF therapy to reduce the risk of immunogenicity and subsequent secondary loss of response to anti-TNF therapy [48]. The use in IBD therapy of the anti-tumor necrosis factor monoclonal antibody recombinant anti-inflammatory cytokines, and related gene therapy are recent advances in the field [49]. Anti-TNF agents have been on the market for more than 15 years and have found an established place in the therapeutic armamentarium, primarily to moderate to severe UC and CD. In CD, evidences suggest that earlier introduction leads to superior outcomes and higher rates of mucosal healing. The latest addition to the anti-TNF class of drugs is golimumab, a subcutaneous human anti-TNF agent that was recently approved by the Food and Drugs Administration (FDA) for the treatment of moderately to severely active UC. Nevertheless, only one third of CD and UC patients show a durable response to all available anti-TNF agents what implicates in a need for novel treatment options. Oral TNF blockers could offer another option [50]. The concomitant use of immunomodulators (methotrexate, azathioprine, and 6-mercaptopurine) when compared to the biologic monotherapy, may increase the systemic exposure and decreases the formation of antibodies to the anti-TNF $\alpha$ agent, consequently enhancing the clinical efficacy. In the other hand, long-term combination therapy with immunomodulators and anti-TNF $\alpha$ agents may lead to increased risks of serious infections and malignancies. The combined therapy for a patient with $\mathrm{CD}$ should always be based on an individualized benefit-risk evaluation [51]. Studies indicate that CD and UC are heterogeneous diseases related to various genetic abnormalities that culminate in overly aggressive T-cell responses to a subset of commensal enteric bacteria. The reinstallation of the disease is provoked by environmental factors that transiently break the mucosal barrier, stimulate immune responses or alter the balance between beneficial and pathogenic enteric bacteria. New insights will help to develop better diagnostic approaches that identify clinically important subsets of patients for whom the natural history of disease and response to therapy are better [52].

\section{Probiotics}

Probiotics are known as viable micro-organisms (or live microorganismsor live microbial dietary supplements) that may promote beneficial physiologic or therapeutic properties when used correctly. The interest in the role of these substances in improving human health is reason of several researches. They may be used to help the immune system, to control gastro-intestinal infections and to prevent several diseases. Authors believe that in a near future, intestinal bacterial flora will be controlled by probiotics but their use needs to be safe using microorganisms with General Recognized as Safe status [6] [53]-[57]. Probiotics may have benefits in inflammation though different ways: 1) production of toxins with antimicrobial properties. For example, L. lactis, produces a bacteriocin able to inhibit genetically distinct $C$. difficile strains; 2 ) modulating intestinal microbiota (Lactobacillus reuteri may prevent colitis in rats because it leads to an increase of the number of lactobacilli in mice gastrointestinal system. Other studies show that $L$. salivarius UCC118 can modify the intestinal microbiota reducing Clostridium perfringens, coliforms, and enterococci and reducing cancer risk; 3) reduction of oxidative stress probably by enhancing the antioxidant enzymes that are usually depressed in IBD patients. A study showed that $L$. rhamnosus CNCM I-3690 is efficient as anti-inflammatory in a model of colitis in vivo (this mi- 
croorganism has antioxidant properties); 4) melioration of the intestinal barrier function because of the improvement of mucus secretion and in the intercellular interactions. It is known that some probiotic may change the expression of mucus secretion; 5) immunomodulatory properties shown by probiotics, which involve regulation, activation, growth, and differentiation of immune cells [6] [58]-[68]. Zagato et al. [62] studied fermented milk with L. paracasei L74 CBA and observed a potential to inhibit production of pro-inflammatory cytokines. Streptococcus salivarius also exhibits anti-inflammatory potential because it has the ability to forbid the activation of the $\mathrm{NF}-\mathrm{Kb}$ [63]. Fernandez et al. [65] showed anti-inflammatory properties in L. salvarius Ls needs NOD2 receptors to exhibit protective effects, which were also related to the local production of IL-10 which has anti-inflammatory properties. Duary et al. [64] showed reduction in the levels of tumor necrosis factor $\alpha$ $(\mathrm{TNF} \alpha)$ and cyclooxygenase-2 (COX-2) and increased IL-10 expression in a model of colitis after using probiotic strain L. plantarum Lp91. Blanc et al. [6] highlight that probiotics effectiveness are "strain dependent and each probiotic should be tested to know if it has specific beneficial effects, and to describe the mechanisms involved in their health-promoting properties". Authors say that it is also important to point that there are mechanisms associated with one individual strain. The Genetic manipulation of probiotics could lead to new treatments for IBD, for example, probiotic lactic acid bacteria (that are the most common microorganisms used as probiotic are lactic acid bacteria) expressing high levels of antioxidant enzymes could help the reduction of oxidative damage, what is useful to treat IBD (for many reasons including alleviation of the symptoms) or to help in the maintenance of remission [69]. Yoshimatsu et al. [70] studied a the use of Bio-Three tablets, each containing 2 $\mathrm{mg}$ of lactomin (Streptococcus faecalis T-110), $10 \mathrm{mg}$ of Clostridium butyricum TO-A, and $10 \mathrm{mg}$ of Bacillus mesentericus TO-A in UC patients in the period of remission and found that probiotics are useful to help the maintenance of clinical remission. The stability and composition of intestinal flora plays a vital role in good health and wellbeing. In order to improve the microbial intestinal environment, several studies have been carried out to evaluate the effect of probiotic administration for the prevention and treatment of various medical conditions [71]. As pointed before, IBD probably result from an inappropriate immunologic response to intestinal bacteria in vulnerable susceptible individuals. Prebiotics, symbiotics, and probiotics have all been studied with growing interest as adjuncts to standard therapies for IBD. In general, probiotics have been shown to be well-tolerated with few side effects, making them a potential attractive treatment option in the management of IBD. Probiotics are microorganisms that are ingested either in combination or as a single organism in an effort to normalize intestinal microbiota and potentially improve intestinal barrier function [72]. Interest in microbiota-based therapy has grown markedly, due in large part to an improved safety profile with fewer side effects when compared to traditional therapy. It is necessary to say that there are only a limited number of well-designed prospective trials that could evaluate potential rare side effects in IBD patients. Collectively, the gut microbiota contains an amount of 1013 to 1014 microorganisms, with the majority (1012 microorganisms) hosted within the colon [73]. Firmicutes and Bacteroidetes are the main bacterial phyla in the gut, comprising about $90 \%$ of the microbiota, followed to a lesser proportion by Actinobacteria, Proteobacteria, Verrucomicrobia, Fusobacteria, and Cyanobacteria [74]. In addition, mucosa-associated bacterial communities in the colon vary highly in composition when compared to those in feces. Recently, researchers have suggested two theories regarding the role of bacteria in pathogenesis of IBD. First, malfunction of the immune system against the bacteria of the intestinal natural florae. Second, alteration in gut microbiota or malfunction of mucosal barrier resulting in harmful immunological responses against mucosa may be implicated in the pathogenesis of IBD [74] [75]. Indeed, it seems that combination of these two mechanisms leads to inflammation and abnormal immune responses, involving alterations in gut microbiota and epithelial-cell function [76] [77]. In addition, clinical evidences have revealed a significant role of gut microbiota, especially florae of distal ileum and colon, in the pathogenesis of IBD [78]. Consumption of probiotic yogurt by patients with IBD may help to improve intestinal function by increasing the number of probiotic bacteria in the intestine and colon [79]). Other studies showed that probiotics, have beneficial effects on host health, probably by improving its intestinal microbial balance. Lactobacilli, Bifidobacteria and Streptococci are commonly used probiotics [80] [81]. Probably, the mechanisms of action of probiotics are: immunomodulation by increase in the number of immunoglobulin-secreting cells in the intestinal mucosa [82]; antibacterial action by production of antibacterial substances action against common pathogens ( $E$. coli, Clostridium difficile and Salmonella spp.) [83] and competitive exclusive by competes with adhesion of pathogens to the intestinal mucosa and makes the colonization of the intestine with beneficial bacteria [84]. The most common adverse effects include bloating and flatulence but these are typically mild and subside with continued use. In IBD numerous culture-independent studies have been carried out recently, comparing the micro- 
biota composition of IBD patients with that of healthy controls [85]. In general, an overall decrease in microbial diversity and stability of the intestinal microbiota has been observed in IBD patients. Specific bacterial species, like Faecalibacterium prausnitzii, have been found to have anti-inflammatory properties, as well as a decreased abundance in IBD patients [86]. Also the function of the microbiota seems to differ between people with CD compared to healthy controls. In the beginning of the 1980s, the results of some investigations demonstrated decreased inactivation of intestinal tryptic activity [87] [88] and reduced levels or absence of tryps in-degrading microbes was hypothesized. People with Crohn's disease have higher levels of fecal trypsin, an enzyme that is produced by the pancreas and which is normally inactivated by the Bacteroides. A better understanding of this interplay may open up for new therapeutic interventions [89].

\section{Conclusion}

Many studies are showing that probiotics may be very helpful for the induction and maintenance of remission in IBD patients. Nevertheless, further researches are necessary to verify how important probiotics are used alone or in combination with other drugs in the prevention, induction and maintenance of remission of IBD patients.

\section{Author Disclosure Statement}

All the authors report no conflicts of interest.

\section{References}

[1] Biasi, F., Leonarduzzi, G., Oteiza, P.I. and Poli, G. (2013) Inflammatory Bowel Disease: Mechanisms, Redox Considerations, and Therapeutic Targets. Antioxidants \& Redox Signaling, 19, 1711-1747. http://dx.doi.org/10.1089/ars.2012.4530

[2] Steinmeyer, S., Lee, K., Jayaraman, A. and Alaniz, R.C. (2015) Microbiota Metabolite Regulation of Host Immune Homeostasis: A Mechanistic Missing Link. Current Allergy and Asthma Reports, 15, 524. http://dx.doi.org/10.1007/s11882-015-0524-2

[3] Okamoto, R. and Watanabe, M. (2015) Role of Epithelial Cells in the Pathogenesis and Treatment of Inflammatory, Bowel Disease. Journal of Gastroenterology. [Epub Ahead of Print] http://dx.doi.org/10.1007/s00535-015-1098-4

[4] Biasi, F., Deiana, M., Guina T., Gamba, P., Leonarduzzi, G. And Poli, G. (2014) Wine Consumption and Intestinal Redox Homeostasis. Redox Biology, 18, 795-802. http://dx.doi.org/10.1016/j.redox.2014.06.008

[5] Wan, Y.C., Li, T., Han, Y.D., Zhang, H.Y., Lin, H. and Zhang, B. (2015) Effect of Pregnane Xenobiotic Receptor Activation on Inflammatory Bowel Disease Treated with Rifaximin. Journal of Biological Regulators and Homeostatic Agents, 29, 401-410.

[6] LeBlanc, A.M., Del Carmen, S., Chatel, J.M., Miyoshi, A., Azevedo, V., Langella, P., Bermúdez-Humarán, L.G. and LeBlanc, J.G. (2015) Current Review of Genetically Modified Lactic Acid Bacteria for the Prevention and Treatment of Colitis Using Murine Models. Gastroenterology Research and Practice, Article ID: 146972. http://dx.doi.org/10.1155/2015/146972

[7] Moller, F.T., Andersen, V., Wohlfahrt, J. and Jess, T. (2015) Familial Risk of Inflammatory Bowel Disease: A Population-Based Cohort Study 1977-2011. The American Journal of Gastroenterology, 110, 564-571. http://dx.doi.org/10.1038/ajg.2015.50

[8] Zhang, Y.Z. and Li, Y.Y. (2014) Inflammatory Bowel Disease: Pathogenesis. World Journal of Gastroenterology, 20, 91-99. http://dx.doi.org/10.3748/wjg.v20.i1.91

[9] Basso, P.J., Fonseca, M.T., Bonfá, G., et al. (2014) Association among Genetic Predisposition, Gut Microbiota, and Host Immune Response in the Etiopathogenesis of Inflammatory Bowel Disease. Brazilian Journal of Medical and Biological Research, 47, 727-737. http://dx.doi.org/10.1590/1414-431X20143932

[10] Tabbaa, M., Golubic, M., Roizen, M.F. and Bernstein, A.M. (2013) Docosahexaenoic Acid, Inflammation, and Bacterial Dysbiosis in Relation to Periodontal Disease, Inflammatory Bowel Disease, and the Metabolic Syndrome. Nutrients, 5, 3299-3310. http://dx.doi.org/10.3390/nu5083299

[11] Brandse, J.F., Vos, L.M., Jansen, J., Schakel, T., Ponsioen, C.I., van den Brink, G.R., D’Haens, G.R. and Löwenberg, M. (2015) Serum Concentration of Anti-TNF Antibodies, Adverse Effects and Quality of Life in Patients with Inflammatory Bowel Disease in Remission on Maintenance Treatment. Journal of Crohn's and Colitis. [Epub ahead of print]

[12] Cheifetz, A.S. (2013) Management of Active Crohn Disease. JAMA, 309, 2150-2158. http://dx.doi.org/10.1001/jama.2013.4466

[13] Molodecky, N.A., Soon, I.S., Rabi, D.M., Ghali, W.A., Ferris, M., Chernoff, G., Benchimol, E.I., Panaccione, R., 
Ghosh, S., Barkema, H.W. and Kaplan, G.G. (2012) Increasing Incidence and Prevalence of the Inflammatory Bowel Diseases with Time, Based on Systematic Review. Gastroenterology, 142, 46-54. http://dx.doi.org/10.1053/j.gastro.2011.10.001

[14] Nadorp, B. and Soreq, H. (2015) Gut Feeling: MicroRNA Discriminators of the Intestinal TLR9-Cholinergic Links. International Immunopharmacology. [Epub ahead of print]

[15] Serhan, C.N. and Savill, J. (2005) Resolution of Inflammation: The Beginning Programs the End. Nature Immunology, 6, 1191-1197. http://dx.doi.org/10.1038/ni1276

[16] De Cruz, P., Prideaux, L., Wagner, J., Ng, S.C., McSweeney, C., Kirkwood, C., et al. (2012) Characterization of the Gastrointestinal Microbiota in Health and Inflammatory Bowel Disease. Inflammatory Bowel Diseases, 18, $372-390$. http://dx.doi.org/10.1002/ibd.21751

[17] Medzhitov, R. (2010) Inflammation 2010: New Adventures of an Old Flame. Cell, 140, 771-776. http://dx.doi.org/10.1016/j.cell.2010.03.006

[18] Nasef, N.A., Mehta, S., Powell, P., Marlow, G., Wileman, T. and Ferguson, L.R. (2015) Extracts of Feijoa Inhibit Toll-Like Receptor 2 Signaling and Activate Autophagy Implicating a Role in Dietary Control of IBD. PLoS ONE, 10, e0130910. http://dx.doi.org/10.1371/journal.pone.0130910

[19] Silverberg, M.S., Satsangi, J., Ahmad, T., Arnott, I.D., Bernstein, C.N., Brant, S.R., Caprilli, R., Colombel, J.F., Gasche, C. and Geboes, K. (2005) Toward an Integrated Clinical, Molecular and Serological Classification of Inflammatory Bowel Disease: Report of a Working Party of the 2005 Montreal World Congress of Gastroenterology. Canadian Journal of Gastroenterology, 19, 5A-36A.

[20] Shores, D.R., Binion, D.G., Freeman, B.A. and Baker, P.R. (2011) New Insights into the Role of Fatty Acids in the Pathogenesis and Resolution of Inflammatory Bowel Disease. Inflammatory Bowel Diseases, 17, 2192-2204. http://dx.doi.org/10.1002/ibd.21560

[21] Pavlov, V.A. and Tracey, K.J. (2012) Thevagus Nerve and the Inflammatory Reflex-Linking Immunity and Metabolism. Nature Reviews Endocrinology, 8, 743-754. http://dx.doi.org/10.1038/nrendo.2012.189

[22] Krieg, A.M. and Vollmer, J. (2007) Toll-Like Receptors 7, 8, and 9: Linking Innate Immunity to Autoimmunity. Immunological Reviews, 220, 251-269. http://dx.doi.org/10.1111/j.1600-065x.2007.00572.x

[23] Bonizzi, G. and Karin, M. (2004) The Two NF- $\kappa$ B Activation Pathways and Their Role in Innate and Adaptive Immunity. Trends in Immunology, 25, 280-288. http://dx.doi.org/10.1016/j.it.2004.03.008

[24] Paraskevi, A., Theodoropoulos, G., Papaconstantinou, I., Mantzaris, G., Nikiteas, N. and Gazouli, M. (2012) Circulating MicroRNA in Inflammatory Bowel Disease. Journal of Crohn's and Colitis, 6, 900-904. http://dx.doi.org/10.1016/j.crohns.2012.02.006

[25] Tas, S.W., Vervoordeldonk, M.J., Hajji, N., Schuitemaker, J.H., van der Sluijs, K.F. and May, M.J. (2007) Noncanonical NF- $\kappa$ B Signaling in Dendritic Cells Is Required for Indoleamine 2,3-Dioxygenase (IDO) Induction and Immune Regulation. Blood, 110, 1540-1549. http://dx.doi.org/10.1182/blood-2006-11-056010

[26] Sailaja, B.S., Cohen-Carmon, D., Zimmerman, G., Soreq, H. and Meshorer, E. (2012) Stress-Induced Epigenetic Transcriptional Memory of Acetylcholinesterase by HDAC4. Proceedings of the National Academy of Sciences of the United States of America, 109, E3687-E3695. http://dx.doi.org/10.1073/pnas.1209990110

[27] Zimmerman, G., Shaltiel, G., Barbash, B., Cohen, J., Gasho, C.J. and Shenhar-Tsarfaty, S. (2012) Post-Traumatic Anxiety Associates with Failure of the Innate Immune Receptor TLR9 to Evade the Pro-Inflammatory NF $\kappa$ B Pathway. Translational Psychiatry, 2, e78. http://dx.doi.org/10.1038/tp.2012.4

[28] Netjes, J.E. and Rijken, M. (2013) Labor Participation among Patients with Inflammatory Bowel Disease. Inflammatory Bowel Diseases, 19, 81-91. http://dx.doi.org/10.1002/ibd.22921

[29] Devlen, J., Beusterien, K., Yen, L., Ahmed, A., Cheifetz, A.S. and Moss, A.C. (2014) Barriers to Mesalamine Adherence in Patients with Inflammatory Bowel Disease: A Qualitative Analysis. J Manag Care Spec Pharm, 20, 309-314.

[30] Bielefeldtand, K., Davis, B. and Binion, D.G. (2009) Pain and Inflammatory Bowel Disease. Inflammatory Bowel Diseases, 15, 778-788. http://dx.doi.org/10.1002/ibd.20848

[31] Aghazadeh, R., Zali, M.R., Bahari, A., Amin, K., Ghahghaie, F. and Firouzi, F. (2005) Inflammatory Bowel Disease in Iran: A Review of 457 Cases. Journal of Gastroenterology and Hepatology, 20, 1691-1695. http://dx.doi.org/10.1111/j.1440-1746.2005.03905.x

[32] Lix, L.M., Graff, L.A., Walker, J.R., Clara, I., Rawsthorne, P., Rogala, L., Miller, N., Ediger, J., Pretorius, T. and Bernstein, C. (2008) Longitudinal Study of Quality of Life and Psychological Functioning for Active, Fluctuating, and Inactive Disease Patterns in Inflammatory Bowel Disease. Inflammatory Bowel Diseases, 14, 1575-1584. http://dx.doi.org/10.1002/ibd.20511

[33] Kappelman, M.D., Rifas-Shiman, S.L., Kleinman, K., Ollendorf, D., Bousvaros, A., Grand, R.J. and Finkelstein, J.A. 
(2007) The Prevalence and Geographic Distribution of Crohn's Disease and Ulcerative Colitis in the United States. Clinical Gastroenterology and Hepatology, 5, 1424-1429. http://dx.doi.org/10.1016/j.cgh.2007.07.012

[34] Burisch, J., Jess, T., Martinato, M. and Lakatos, P. (2013) The Burden of Inflammatory Bowel Disease in Europe, on Behalf of ECCO-EpiCom. Journal of Crohn's and Colitis, 7, 322-337. http://dx.doi.org/10.1016/j.crohns.2013.01.010

[35] Matricon, J. (2010) Immunopathogenèse des maladies inflammatoireschroniques de l'intestin. M/S n ${ }^{\circ}$ 4, vol. 26.

[36] Lorén, V., Cabré, E., Ojanguren, I., Domènech, E., Pedrosa, E., García-Jaraquemada, A., et al. (2015) Interleukin-10 Enhances the Intestinal Epithelial Barrier in the Presence of Corticosteroids through p38 MAPK Activity in Caco-2 Monolayers: A Possible Mechanism for Steroid Responsiveness in Ulcerative Colitis. PLoS ONE, 10, e130921. http://dx.doi.org/10.1371/journal.pone.0130921

[37] Longui, C.A. (2007) Glucocorticoid Therapy: Minimizing Side Effects. Jornal de Pediatria, 83, S163-S171. http://dx.doi.org/10.2223/jped.1713

[38] Brunton, L.L., Chabner, B.A. and Knollmann, B.C. (2012) Goodman \& Gilman's The Pharmacological Basis of Therapeutics. 12th Edition, AMGH Editora, Porto Alegre.

[39] Moss, A.C. and Peppercorn, M.A. (2007) The Risks and the Benefits of Mesalazine as a Treatment for Ulcerative Colitis. Expert Opinion on Drug Safety, 6, 99-107. http://dx.doi.org/10.1517/14740338.6.2.99

[40] Feagan, B.G., Chande, N. and MacDonald, J.K. (2009) Are There Any Differences in the Efficacy and Safety of Different Formulations of Oral 5-ASA Used for Induction and Maintenance of Remission in Ulcerative Colitis? Evidence from Cochrane Reviews. Inflammatory Bowel Diseases, 19, 2031-2040.

[41] Kawashima, K., Ishihara, S., Yuki, T., Onishi, K., Kushiyama, Y., Fujishiro, H., et al. (2014) Therapeutic Efficacy of $\mathrm{pH}$-Dependent Release Formulation of Mesalazine on Active Ulcerative Colitis Resistant to Time-Dependent Release Formulation: Analysis of Fecal Calprotectin Concentration. BioMed Research International, 2014, Article ID: 342751. http://dx.doi.org/10.1155/2014/342751

[42] Riley, S.A., Tavares, I.A., Bennett, A. and Mani, V. (1988) Delayed-Release Mesalazine (5-Aminosalicylic Acid): Coat Dissolution and Excretion in Ileostomy Subjects. British Journal of Clinical Pharmacology, 26, 173-177. http://dx.doi.org/10.1111/j.1365-2125.1988.tb03383.x

[43] Fernandez-Becker, N.Q. and Moss, A.C. (2008) Improving Delivery of Aminosalicylates in Ulcerative Colitis: Effect on Patient Outcomes. Drugs, 68, 1089-1103. http://dx.doi.org/10.2165/00003495-200868080-00006

[44] D’Incà, R., Paccagnella, M., Cardin, R., Pathak, S., Baldo, V., Giron, M.C. and Sturniolo, G.C. (2013) 5-ASA Colonic Mucosal Concentrations Resulting from Different Pharmaceutical Formulations in Ulcerative Colitis. World Journal of Gastroenterology, 19, 5665-5670. http://dx.doi.org/10.3748/wjg.v19.i34.5665

[45] Thomas, C.W., Myhre, G.M., Tschumper, R., Sreekumar, R., Jelinek, D., McKean, D.J., Lipsky, J.J., Sandborn, W.J. and Egan, L.J. (2005) Selective Inhibition of Inflammatory Gene Expression in Activated T Lymphocytes: A Mechanism of Immune Suppression by Thiopurines. Journal of Pharmacology and Experimental Therapeutics, 312, 537-545. http://dx.doi.org/10.1124/jpet.104.074815

[46] Engelhardt, B. and Briskin, M.J. (2005) Therapeutic Targeting of $\alpha 4$-Integrins in Chronic Inflammatory Diseases: Tipping the Scales of Risk towards Benefit? European Journal of Immunology, 35, 2268-2273. http://dx.doi.org/10.1002/eji.200535195

[47] Swaminath, A., Taunk, R. and Lawlor, G. (2014) Use of Methotrexate in Inflammatory Bowel Disease in 2014: A User's Guide. World Journal of Gastrointestinal Pharmacology and Therapeutics, 5, 113-121. http://dx.doi.org/10.4292/wjgpt.v5.i3.113

[48] Wahed, M., Louis-Auguste, J.R., Baxter, L.M., Limdi, J.K., McCartney, S.A., Lindsay, J.O. and Bloom, S.L. (2009) Efficacy of Methotrexate in Crohn's Disease and Ulcerative Colitis Patients Unresponsive or Intolerant to Azathioprine/Mercaptopurine. Alimentary Pharmacology \& Therapeutics, 30, 614-620. http://dx.doi.org/10.1111/j.1365-2036.2009.04073.x

[49] Absah, I. and Faubion, W.A. (2012) Concomitant Therapy with Methotrexate and Anti-TNF- $\alpha$ in Pediatric Patients with Refractory Crohn's Colitis: A Case Series. Inflammatory Bowel Diseases, 18, 1488-1492. http://dx.doi.org/10.1002/ibd.21885

[50] Ko, J.K. and Auyeung, K.K. (2014) Inflammatory Bowel Disease: Etiology, Pathogenesis and Current Therapy. Current Pharmaceutical Design, 20, 1082-1096. http://dx.doi.org/10.2174/13816128113199990416

[51] Löwenberg, M. and D'Haens, G. (2015) Next-Generation Therapeutics for IBD. Current Gastroenterology Reports, 17, 21. http://dx.doi.org/10.1007/s11894-015-0444-2

[52] Xu, Z., Davis, H.M. and Zhou, H. (2015) Clinical Impact of Concomitant Immunomodulators on Biologic Therapy: Pharmacokinetics, Immunogenicity, Efficacy and Safety. Journal of Clinical Pharma, 55, S60-S74. http://dx.doi.org/10.1002/jcph.380

[53] Actis, G.C., Pellicano, R. and Rosina, F. (2015) Inflammatory Bowel Disease: Traditional Knowledge Holds the Seeds 
for the Future. World Journal of Gastrointestinal Pharmacology and Therapeutics, 6, 10-16. http://dx.doi.org/10.4292/wjgpt.v6.i2.10

[54] Gungor, O.E., Kirzioglu, Z. and Kivanc, M. (2015) Probiotics: Can They Be Used to Improve Oral Health? Beneficial Microbes. [Epub ahead of print]

[55] Fujimori, S. (2015) What Are the Effects of Proton Pump Inhibitors on the Small Intestine? World Journal of Gastroenterology, 21, 6817-6819.

[56] Petrof, E.O. and Khoruts, A. (2014) From Stool Transplants to Next-Generation Microbiota Therapeutics. Gastroenterology, 146, 1573-1582. http://dx.doi.org/10.1053/j.gastro.2014.01.004

[57] Khoruts, A., Dicksved, J., Jansson, J.K. and Sadowsky, M.J. (2010) Changes in the Composition of the Human Fecal Microbiome after Bacteriotherapy for Recurrent Clostridium Difficile-Associated Diarrhea. Journal of Clinical Gastroenterology, 44, 354-360.

[58] Ng, S.C., Hart, A.L., Kamm, M.A., Stagg, A.J. and Knight, S.C. (2009) Mechanisms of Action of Probiotics: Recent Advances. Inflammatory Bowel Diseases, 15, 300-310. http://dx.doi.org/10.1002/ibd.20602

[59] Caballero-Franco, C.K., Simone, K.C.D. and Chadee, K. (2007) The VSL\#3 Probiotic Formula Induces Mucin Gene Expression and Secretion in Colonic Epithelial Cells. The American Journal of Physiology — Gastrointestinal and Liver Physiology, 292, G315-G322. http://dx.doi.org/10.1152/ajpgi.00265.2006

[60] Kruidenier, L. and Verspaget, H.W. (2002) Review Article: Oxidative Stress as a Pathogenic Factor in Inflammatory Bowel Disease - Radicals or Ridiculous? Alimentary Pharmacology and Therapeutics, 16, 1997-2015. http://dx.doi.org/10.1046/j.1365-2036.2002.01378.x

[61] Grompone, G.P. and Llopis, S.M. (2012) Anti-Inflammatory Lactobacillus rhamnosus CNCM I-3690 Strain Protects against Oxidative Stress and Increases Lifespan in Caenorhabditis elegans. PLoS ONE, 7, e52493. http://dx.doi.org/10.1371/journal.pone.0052493

[62] Zagato, E., Mileti, E. and Massimiliano, L. (2014) Lactobacillus Paracasei CBA L74 Metabolic Products and Fermented Milk for Infant Formula Have Anti-Inflammatory Activity on Dendritic Cells in Vitro and Protective Effects against Colitis and an Enteric Pathogen in Vivo. PLoS ONE, 9, e87615. http://dx.doi.org/10.1371/journal.pone.0087615

[63] Kaci, G., Goudercourt, D. and Dennin, V. (2014) Anti-Inflammatory Properties of Streptococcus salivarius, a Commensal Bacterium of the Oral Cavity and Digestive Tract. Applied and Environmental Microbiology, 80, 928-934. http://dx.doi.org/10.1128/AEM.03133-13

[64] Duary, R.K., Bhausaheb, M.A., Batish, V.K. and Grover, S. (2012) Anti-Inflammatory and Immunomodulatory Efficacy of Indigenous Probiotic Lactobacillus plantarum Lp91 in Colitis Mouse Model. Molecular Biology Reports, 39, 4765-4775. http://dx.doi.org/10.1007/s11033-011-1269-1

[65] Fernandez, E.M., Valenti, V. and Rocke, C. (2011) Anti-Inflammatory Capacity of Selected Lactobacilli in Experimental Colitis Is Driven by NOD2-Mediated Recognition of a Specific Peptidoglycan-Derived Muropeptide. Gut, 60, 1050-1059. http://dx.doi.org/10.1136/gut.2010.232918

[66] Chaves, S., Perdigon, G. and LeBlanc, A.M. (2011) Yoghurt Consumption Regulates the Immune Cells Implicated in Acute Intestinal Inflammation and Prevents the Recurrence of the Inflammatory Process in a Mouse Model. Journal of Food Protection, 74, 801-811. http://dx.doi.org/10.4315/0362-028X.JFP-10-375

[67] Rea, M.C., Clayton, E. and O'Connor, P.M. (2007) Antimicrobial Activity of Lacticin 3147 against Clinical Clostridium Difficile Strains. Journal of Medical Microbiology, 56, 940-946. http://dx.doi.org/10.1099/jmm.0.47085-0

[68] O’Mahony, L., Feeney, M. and O'Halloran, S. (2001) Probiotic Impact on Microbial Flora, Inflammation and Tumour Development in IL-10 Knockout Mice. Alimentary Pharmacology and Therapeutics, 15, 1219-1225. http://dx.doi.org/10.1046/j.1365-2036.2001.01027.x

[69] Hill, C., Guarner, F. and Reid, G. (2014) Expert Consensus Document: The International Scientific Association for Probiotics and Prebiotics Consensus Statement on the Scope and Appropriate Use of the Term Probiotic. Nature Reviews Gastroenterology \& Hepatology, 11, 506-514. http://dx.doi.org/10.1038/nrgastro.2014.66

[70] Yoshimatsu, Y., Yamada, A., Furukawa, R., Sono, K., Osamura, A., Nakamura, K., Aoki, H., Tsuda, Y., Hosoe, N., Takada, N. and Suzuki, Y. (2015) Effectiveness of Probiotic Therapy for the Prevention of Relapse in Patients with Inactive Ulcerative Colitis. World Journal of Gastroenterology, 21, 5985-5994.

[71] Cruchet, S., Furnes, R., Maruy, A., Hebel, E., Palacios, J., Medina, F., et al. (2015) The Use of Probiotics in Pediatric Gastroenterology: A Review of the Literature and Recommendations by Latin-American Experts. Paediatric Drugs, 17, 199-216. http://dx.doi.org/10.1007/s40272-015-0124-6

[72] Ghouri, Y.A., Richards, D.M., Rahimi, E.F., Krill, J.T., Jelinek, K.A. and DuPont, A.W. (2014) Systematic Review of Randomized Controlled Trials of Probiotics, Prebiotics, and Synbiotics in Inflammatory Bowel Disease. Clinical and Experimental Gastroenterology, 7, 473-487.

[73] Sartor, R.B. (2008) Microbial Influences in Inflammatory Bowel Diseases. Gastroenterology, 134, 577-594. 
http://dx.doi.org/10.1053/j.gastro.2007.11.059

[74] Eckburg, P.B., Bik, E.M., Bernstein, C.N., Purdom, E., Dethlefsen, L., Sargent, M., et al. (2005) Diversity of the Human Intestinal Microbial Flora. Science, 308, 1635-1638. http://dx.doi.org/10.1126/science.1110591

[75] Asakura, H., Suzuki, K. and Honma, T. (2007) Recent Advances in Basic and Clinical Aspects of Inflammatory Bowel Disease: Which Steps in the Mucosal Inflammation Should We Block for the Treatment of Inflammatory Bowel Disease? World Journal of Gastroenterology, 13, 2145-2149. http://dx.doi.org/10.3748/wjg.v13.i15.2145

[76] Steer, T., Carpenter, H., Tuohy, K. and Gibson, G.R. (2000) Perspectives on the Role of the Human Gut Microbiota and Its Modulation by Pro- and Prebiotics. Nutrition Research Reviews, 13, 229-254. http://dx.doi.org/10.1079/095442200108729089

[77] Othman, M., Agüero, R. and Lin, H.C. (2008) Alterations in Intestinal Microbial Flora and Human Disease. Current Opinion in Gastroenterology, 24, 11-16. http://dx.doi.org/10.1097/mog.0b013e3282f2b0d7

[78] Mai, V. and Draganov, P.V. (2009) Recent Advances and Remaining Gaps in Our Knowledge of Associations between Gut Microbiota and Human Health. World Journal of Gastroenterology, 15, 81-85. http://dx.doi.org/10.3748/wjg.15.81

[79] Shadnoush, M., Hosseini, R.S., Khalilnezhad, A., Navai, L., Goudarzi, H. and Vaezjalali, M. (2015) Effects of Probiotics on Gut Microbiota in Patients with Inflammatory Bowel Disease: A Double-Blind, Placebo-Controlled Clinical Trial. The Korean Journal of Gastroenterology, 65, 215-221. http://dx.doi.org/10.4166/kjg.2015.65.4.215

[80] Gibson, G.R. and Roberfroid, M.B. (1995) Dietary Modulation of the Human Colonic Microbiota: Introducing the Concept of Prebiotics. Journal of Nutrition, 125, 1401-1412.

[81] O’Mahony, L., Feeney, M., O’Halloran, S., Murphy, L., Kiely, B., Fitzgibbon, J., et al. (2001) Probiotic Impact on Microbial Flora, Inflammation and Tumour Development in IL-10 Knockout Mice. Alimentary Pharmacology and Therapeutics, 15, 1219-1225. http://dx.doi.org/10.1046/j.1365-2036.2001.01027.x

[82] Guarino, A., Vecchio, A.L. and Canani, R.B. (2009) Probiotics as Prevention and Treatment for Diarrhea. Current Opinion in Gastroenterology, 25, 18-23. http://dx.doi.org/10.1097/mog.0b013e32831b4455

[83] Indriyani, S. (2012) Effects of Live versus Heat-Killed Probiotics on Acute Diarrhea in Young Children. Paediatrica Indonesiana, 52, 249-254. http://dx.doi.org/10.14238/pi52.5.2012.01

[84] Lutgendorff, F., Akkermans, L. and Soderholm, J. (2008) The Role of Microbiota and Probiotics in Stress-Induced Gastro-Intestinal Damage. Current Molecular Medicine, 282-298. http://dx.doi.org/10.2174/156652408784533779

[85] Gerritsen, J., Smidt, H., Rijkers, G.T. and de Vos, W.M. (2011) Intestinal Microbiota in Human Health and Disease: The Impact of Probiotics. Genes \& Nutrition, 6, 209-240. http://dx.doi.org/10.1007/s12263-011-0229-7

[86] Scaldaferri, F., Gerardi, V., Lopetuso, L.R., Del Zompo, F., Mangiola, F., Boskoski, I., et al. (2013) Gut Microbial Flora, Prebiotics, and Probiotics in IBD: Their Current Usage and Utility. BioMed Research International, 2013, Article ID: 435268. http://dx.doi.org/10.1155/2013/435268

[87] Bergstrand, L.O., Gustafsson, B.E., Holmstrom, B. and Norin, K.E. (1981) The Physiological Activity of Human Ileal Flora in Patients with Crohn's Disease and Ulcerative Colitis Evaluated by Determination of Germfree Animal Characteristics. Actachirscand, 147, 707-709.

[88] Van der Merve, J.P. and Mol, G.J.J. (1982) Levels of Trypsin and Alpha-Chymotrypsin in Feces from Patients with Crohn's Disease. Digestion, 24, 1-4. http://dx.doi.org/10.1159/000198767

[89] Midtvedt, T., Zabarovsky, E., Norin, E., Bark, J., Gizatullin, R., Kashuba, V., et al. (2013) Increase of Faecal Tryptic Activity Relates to Changes in the Intestinal Microbiome: Analysis of Crohn's Disease with a Multidisciplinary Platform. PLoS ONE, 8, e66074. http://dx.doi.org/10.1371/journal.pone.0066074 